\title{
CONF.970834--14
}

\section{ELEMENTAL MAPPING AT GRAIN BOUNDARIES IN ALLOY X-750 BY EFTEM}

\author{
J. Bentley,* N. D. Evans, $†$ and E. A. Kenik* \\ * Metals \& Ceramics Division, Oak Ridge National Laboratory, PO Box 2008, Oak Ridge, TN 37831-6376 \\ fOak Ridge Institute for Science and Education, PO Box 117, Oak Ridge, TN 37831-0117
}

Alloy X-750 is a $\gamma^{\prime}$-strengthened, nickel-base alloy used in demanding high-temperature applications. The HTH commercial heat treatment condition provides excellent strength and good corrosion resistance. However, the resultant precipitate structure is complex with fine $(-20 \mathrm{~nm})$ intragranular $\gamma^{\prime}$ phase and copious intergranular precipitation of at least four phases $\left(\gamma^{\prime}, \mathrm{M}_{23} \mathrm{C}_{6}, \mathrm{M}_{23} \mathrm{~B}_{6}\right.$, and TiN). ${ }^{1}$ The intergranular precipitation causes localized grain boundary migration and results in a convoluted grain boundary structure. Such complex grain boundary microstructures increase the difficulty of phase identification and interfacial composition measurements by traditional analytical electron microscopy methods. $^{2}$ Elemental mapping by EFTEM is a useful additional or alternative technique for characterizing such structures. $^{2}$ A Gatan Imaging Filter (GIF) on a Philips CM30 (LaB6) was used in the current investigation. Experimental details have been summarized elsewhere. ${ }^{3}$

Elemental maps of $\mathrm{Cr}, \mathrm{Ti}$, and $\mathrm{Ni}$ (net $\mathrm{L}_{23}$ intensities) are presented in Fig. 1a-c for a typical grain boundary region of a $\mathrm{HTH}$ heat treated specimen. The $\mathrm{M}_{23} \mathrm{C}_{6}$ phase is rich in $\mathrm{Cr}$ and contains virtually no $\mathrm{Ti}$ or $\mathrm{Ni}$. The fine intragranular and coarse intergranular $\gamma^{\prime}$ particles are strongly depleted in $\mathrm{Cr}$, highly enriched in $\mathrm{Ti}$, and slightly enriched in $\mathrm{Ni}$, relative to the matrix. The large intergranular "precipitate" at the right side of the images is a two-phase particle; the outer rim is Cr-rich $\mathrm{M}_{23} \mathrm{C}_{6}$, whereas the central portion is $\mathrm{M}_{23} \mathrm{~B}_{6} \tau$ phase that is enriched in $\mathrm{Ni}$ and $\mathrm{Ti}$ and strongly depleted in $\mathrm{Cr}$. These phases are indistinguishable by routine TEM imaging and microdiffraction; they are isostructural, have almost identical lattice parameters, and are oriented cube-on-cube. However, such two-phase particles have been previously identified and characterized by conventional EDS and PEELS microanalysis. ${ }^{1}$ Jump-ratio maps for C and B (Fig. 1d,e) confirm the nature of the two-phase particle. The generation of artifact-free elemental maps for $C$ and $B$ was not successful, even with logpolynomial fitting of the pre-edge background for a series of energy-filtered images. ${ }^{4}$

In regions free of second phases the grain boundary exhibits $\mathrm{Cr}$ depletion, as shown by the profile in Fig. If from the region indicated in Fig. 1a. Corrections for thickness and diffraction contrast ${ }^{3}$ result in minimal changes. The intergranular $\mathrm{Cr}$ depletion, which is important because it can result in a localized loss of corrosion resistance, was confirmed by spectrum lines $(-1 \mathrm{~nm}$ diam. probe) recorded with the use of a Philips CM200FEG, Gatan 666 PEELS, and EMiSPEC Vision integrated acquisition system. The net $\mathrm{Cr} \mathrm{L}_{23}$ intensity profile is also shown in Fig. If, but direct comparison with the EFTEM profile is not possible because of slight differences in specimen orientation. The spectrumline data also revealed a similar depletion in Fe but a uniform oxygen signal (from surface oxide). Since the oxygen edge is in the $\mathrm{Cr}$ pre-edge region used for background fitting, artifacts that are difficult to assess may be produced in EFTEM Cr elemental maps. In the acquisition of meaningful spectrum lines it is critical to avoid $\gamma^{\prime}$ particles, but under the weak diffracting conditions required for optimum microanalysis it is virtually impossible to image the $\gamma^{\prime}$ particles. The EFTEM elemental maps were most helpful in selecting appropriate analysis locations. The use of spectrum images rather than spectrum lines should similarly cope with such complex microstructures, but at the moment the absence of drift correction during the lengthy acquisition precludes their practical viability. ${ }^{5}$

1 E.A. Kenik, these proceedings; also Mater. Res. Soc. Symp. Proc. 439, in press.

2 E.L. Hall and J. Bentley, Mater. Res. Soc. Symp. Proc. 458, in press.

3 J. Bentley et al. Proc. Microscopy and Microanalysis 1996, 542.

4 N.D. Evans and J. Bentley, Proc. Microscopy and Microanalysis 1996, 544.

5 Research at the ORNL SHaRE User Facility sponsored by the Division of Materials Sciences, U.S. Department of Energy, under contracts DE-AC05-96OR22464 with Lockheed Martin Energy Research Corp., and DE-AC05-76OR00033 with Oak Ridge Associated Universities.

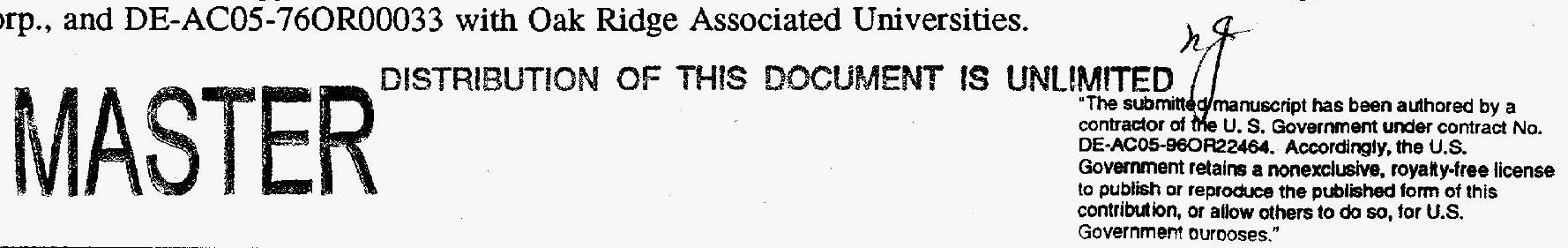




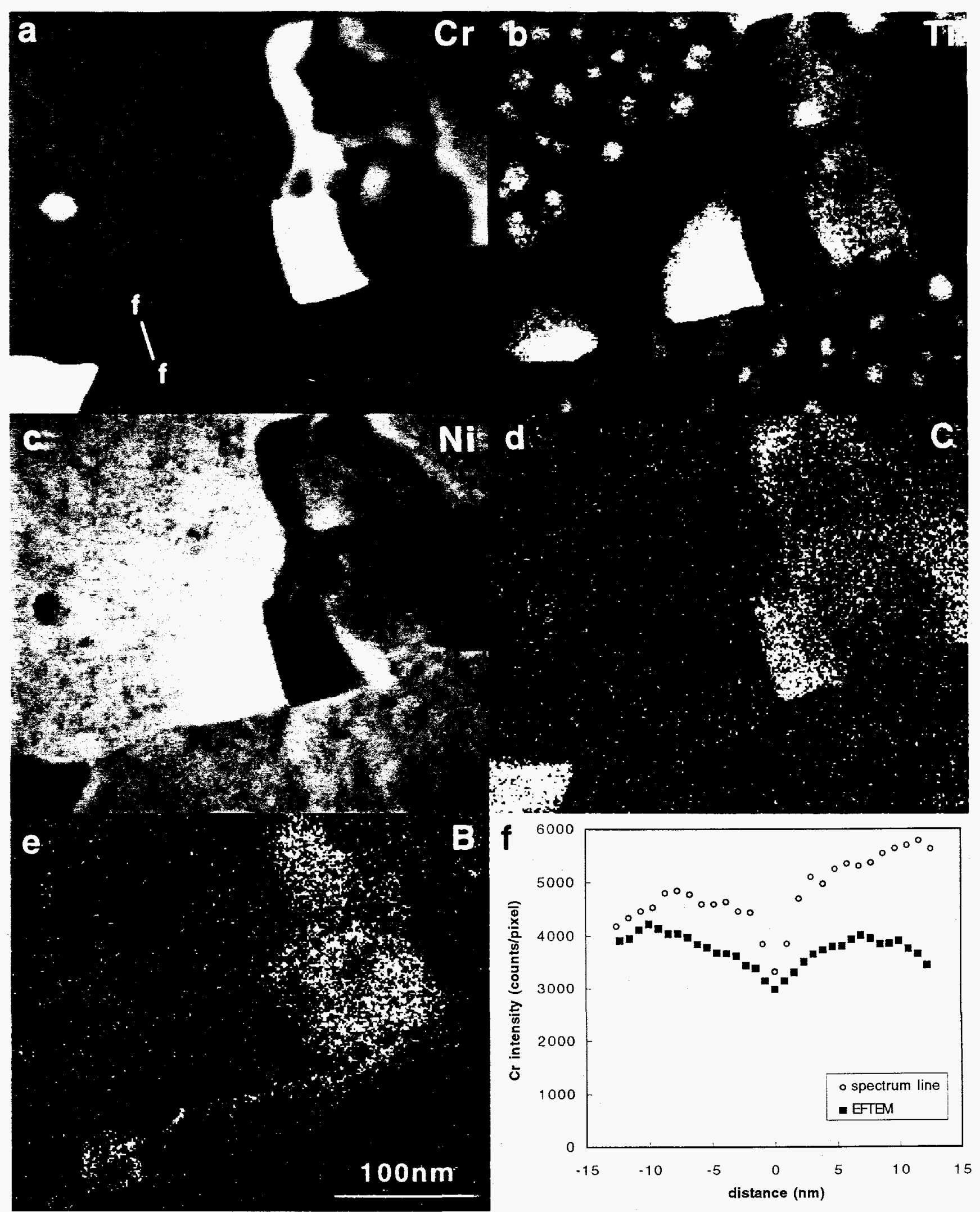

FIG. 1 - Elemental maps of (a) $\mathrm{Cr}$, (b) Ti, and (c) Ni; jump-ratio maps for (d) $\mathrm{C}$ and (e) B; (f) grain boundary $\mathrm{Cr}$ depletion profiles measured by EFTEM [position marked on (a)] and by PEELS spectrum line (see text). 


\section{DISCLAIMER}

This report was prepared as an account of work sponsored by an agency of the United States Government. Neither the United States Government nor any agency thereof, nor any of their employees, makes any warranty, express or implied, or assumes any legal liability or responsibility for the accuracy, completeness, or usefulness of any information, apparatus, product, or process disclosed, or represents that its use would not infringe privately owned rights. Reference herein to any specific commercial product, process, or service by trade name, trademark, manufacturer, or otherwise does not necessarily constitute or imply its endorsement, recommendation, or favoring by the United States Government or any agency thereof. The views and opinions of authors expressed herein do not necessarily state or reflect those of the United States Government or any agency thereof. 


\section{DISCLAMIER}

Portions of this document may be illegible in electronic image products. Images are produced from the best available original document. 